\title{
RUANG KONSOLIDASI MASYARAKAT
}

\author{
Helena Andriani ${ }^{1)}$, Franky Liauw ${ }^{2)}$ \\ 1)Program Studi S1 Arsitektur, Fakultas Teknik, Universitas Tarumanagara, katarinahelena96@gmail.com \\ 2) Program Studi S1 Arsitektur, Fakultas Teknik, Universitas Tarumanagara, frankyl@ft.untar.ac.id
}

\begin{abstract}
Abstrak
Pembangunan pusat perbelanjaan di Jakarta meroket beberapa tahun terakhir. Menjamurnya pusat perbelanjaan ini dikarenakan pusat perbelanjaan atau shopping center menjadi tujuan utama bagi pengunjungnya yang ingin mencari entertainment atau sarana hiburan lainnya. Proyek ini bertujuan untuk menawarkan sebuah wadah dimana pengunjung dapat memperluas koneksi, meningkatkan interaksi sosial dan mempererat hubungan antara satu penduduk dengan lainnya. Fasilitas hiburan tentunya bisa dikembangkan tidak hanya berupa pusat perbelanjaan, melainkan menjadi sesuatu yang dikemas menarik dan memperkuat hubungan antar pengunjungnya dan pengunjung yang tinggal disekitarnya. Dengan membuat fasilitas hiburan yang terletak di tengah pemukiman warga, diharapkan bisa mempererat hubungan antar penduduk sehingga penduduk dengan datang, bermain dan menggunakan fasilitas sebagai salah satu cara untuk networking satu dengan yang lainnya.
\end{abstract}

Kata kunci: bermain; main; mal; menarik; ramah

\begin{abstract}
The construction of shopping centers in Jakarta has skyrocketed in the past few years. The proliferation of shopping centers mainly caused by shopping centers has been the main destination for visitors, wanting an all in one solution for entertainment. This project aims to offer a new space allowing its visitor to network, increase social interaction and strenghten the bonds between one another. Entertainment facilities can certainly be developed not only in the form of shopping centers, but into something that is packaged attractively and strengthens the relationship between visitors and visitors who live nearby. By creating an new form of entertainment facilities located in the middle of residential areas, it is expected to create the true third place in Kelapa Gading area, so that residents can come, play and use the facilities as a way to network with one another.
\end{abstract}

Keywords: engaging; mall; play; playful; sociable

\section{PENDAhuluAN}

Oldenburg dan Habermas sama-sama berpendapat bahwa ada sebuah area di mana didalamnya, berbagai lapisan masyarakat saling berinteraksi satu dengan yang lainnya, menjaga hubungan sosial. Area itu kemudian dinamakan third Place oleh Oldenburg untuk memisahkan antara tempat tinggal (first place) dan tempat bekerja (second place) dalam pembahasan. third place sendiri berakar dari konsep public realm sebagai ruang di mana berbeda pendapat justru bersatu karena mereka berbeda (Habermas, 1989). Beberapa contoh sederhana dari third place adalah café, bar, dan salon kecantikan (Oldenburg, 1989). Di dalam contoh-contoh tersebut, manusia saling berinteraksi melalui percakapan tentang berbagai macam topik satu dengan yang lainnya. Beberapa karakteristik dari sebuah third place adalah tempat yang netral, status sosial tidaklah penting didalamnya, percakapan adalah interaksi utama di dalamnya tetapi bukan satu-satunya, tempatnya terbuka dan mengakomodasi, memiliki pengunjung tetap, low profile, playful, dan home away from home (Myers, 2012). 
Karakteristik - karakteristik ini diuraikan sebelum teknologi informasi dan komunikasi menjadi tersebar luas dan terintegrasi ke dalam jalinan kehidupan sehari-hari (Weiser, 1991). Berdasarkan karakteristik dari third place oleh Oldenburg, disebutkan salah satunya adalah memiliki pengunjung tetap. Poin seutuhnya berbunyi "memiliki sejumlah pengunjung tetap yang menghidupkan tempat, memberikan nada dan karakteristik lalu menyambut pengguna baru" (Myers, 2012).

Sebelum digarap pengembang menjadi pemukiman, kawasan ini merupakan sebuah rawarawa. Setelah pengembang selesai membangun pemukiman dipasarkan, developer kemudian membangun sebuah mal tahun 1990 yang berkonsep one stop entertaiment: pasar swalayan, toko pakaian, pujasera dan tempat bermain anak. Menurut riset Properti Kompas, mal yang sekarang memegang predikat mal terluas di Jakarta ini pada masa itu merupakan mal satusatunya yang berkonsep one stop shopping and entertaining solution untuk memberikan kepraktisan dalam konteks tempat hiburan karena memuat berbagai aspek seperti tempat berbelanja kebutuhan pokok, gaya hidup dan tempat bermain anak. Hal ini bertahan selama beberapa tahun dan selama beberapa tahun ini penduduk di kawasan Kelapa Gading mengandalkan mal ini sebagai tempat hiburan dan bersosialisasi hingga saat ini. Environment dalam konteks hiburan di kawasan Kelapa Gading perlahan mempengaruhi penduduk di Kawasan Kelapa Gading membentuk behaviour yang mencari mal sebagai tempat hiburan. Saat ini, orang percaya bahwa mal adalah tempat terbaik untuk nongkrong dan entertaiment. Bukan hanya tempat untuk berbelanja tetapi juga untuk sosial dan kegiatan rekreasi (Monisha, Divyalakshmi, Divyaa: 2019 p. 56-57).

\section{KAJIAN LITERATUR}

Third place memiliki banyak fungsi yang penting baik bagi individu maupun masyarakat di sekitar tempat tinggalnya. Fungsi-fungsi dari third place adalah:

a. Third place membantu menyatukan lingkungan, ketika tidak adanya third place didalam suatu tempat, orang-orang akan hidup first place dan second place selama bertahun-tahun dan mereka tidak mengenal satu sama lain;

b. Third place berfungsi sebagai "ports of entry" bagi pengunjung baru untuk memperoleh informasi dan sebagai sarana berkenalan dengan cepat dan belajar where things are dan mengetahui how the neighbourhood works;

c. Third place sebagai penyatu komunitas, e.g. seorang pemancing, seorang musisi amatir, seorang perenang dapat menemukan komunitasnya di lingkungan itu dan menemukan tempat lain untuk menyalurkan minat dan bakat mereka;

d. Third place bisa membawa berbagai jenjang usia bersatu dan saling berinteraksi;

e. Third place membantu menjaga sebuah lingkungan. Orang yang menggunakan third place sebagai second place, akan tentunya mengenal pengguna dari third place itu; Mereka kenal semua orang di lingkungan; mereka mengawasi anak-anak setempat saat bermain, $d s b$;

f. Third place sebagai tempat hiburan, dan hiburannya disediakan oleh penggunanya sendiri. Aktivitas utama didalam third place merupakan percakapan, percakapan sendiri bisa mengarah menuju lelucon, informasi, dll yang memberikan kita hiburan secara langsung (Oldenburg, 1997).

Kriteria A True Third Place (Myers, 2012)

Dalam bukunya The Great Good Places, Oldenburg memberikan berbagai karakteristik tentang sebuah third place yang menjadi jangkar dalam komunitas, memberikan interaksi yang lebih luas dan kreatif. Karakteristik itu disimpulkan:

a. Neutral ground: tidak memiliki kewajiban untuk datang kesana, ada di sebuah lokasi yang tidak terikat dengan politik, finansial, dan hukum, pengunjung bebas datang dan pergi sesukanya; 
b. A levelling place third place: tidak mementingkan status sosial dan ekonomi, semua sama rata didalamnya;

c. Diisi oleh interaksi berupa percakapan: interaksi didalam third place tidak hanya percakapan, namun percakapan menjadi interaksi utama;

d. Terbuka dan mudah diakses: selalu terbuka dan mudah diakses oleh penggunanya dan juga mengakomodasi penghuninya sehingga kebutuhannya terpenuhi;

e. Adanya reservoir of regulars: memiliki sejumlah pengunjung tetap yang menghidupkan tempat, memberikan nada, warna dan karakteristik serta menyambut pengguna baru;

f. Low profile: memiliki rasa homey dan tidak ada sesuatu yang luar biasa mewah atau megah, menerima pengunjung dari berbagai lapisan masyarakat;

g. Mood nya playful (menyenangkan): third place hadir karena pengunjungnya yang ingin merasakan kembali suasana disana;

h. Home away from home: pengguna memiliki rasa kehangatan dan kepemilikan seperti yang mereka rasakan di tempat tinggalnya sehingga mampu mendapatkan regenerasi spiritual dengan menghabiskan waktu disana.

\section{Third place dan Teknologi}

Kedai kopi, bar, dan tempat pangkas rambut adalah beberapa contoh third place yang dinamai oleh Oldenburg (1996). Menurutnya, tempat-tempat ini bukan tempat kerja, bukan rumah melainkan tempat-tempat di mana masyarakat setempat berkumpul untuk bersantai dan membahas berbagai topik. Tempat-tempat ini mengungkap kehidupan dari masyarakat. Sebagaimana dibahas oleh Oldenburg, karakteristik third pace adalah low profile, netral, inklusif, mudah diakses, akomodatif, diisi dengan pelanggan tetap, didominasi percakapan, dan playful.

Karakteristik ini diuraikan sebelum Teknologi Informasi dan Komunikasi (TIK) seperti Internet, ponsel, dan layanan jejaring sosial (SNS) [? -misalnya, Facebook dan Twittermenjadi tersebar luas dan terintegrasi ke dalam "jalinan kehidupan sehari-hari" (Weiser, 1991). Oldenburg sudah memberikan karakteristik prototype dari jejaring sosial. Misalnya, Facebook atau Twitter (Soukup, 2006) memiliki banyak karakteristik yang cocok dengan yang menggambarkan third place, misalnya, semuanya inklusif karena siapa pun yang memiliki akun dapat memposting komentar dan pendapatnya tentang topik apa pun yang menarik; Facebook dapat diakses dengan mengizinkan siapa saja untuk mencari profil orang, sementara Twitter memungkinkan pencarian publik untuk tweet; kedua jejaring sosial fokus pada memungkinkan terjadinya percakapan dan diskusi; dan kedua jaringan menawarkan beragam topik yang melayani audiens yang berbeda." (Memarovic et al, 2014)

\section{Consumer Behaviour}

Perilaku konsumerisme menjadi dalang para investor dan pengembang memiliki pola pikir "bangunlah mal, maka konsumen akan datang". Penting bagi pengembang untuk mempelajari perilaku konsumen sehingga bisa membedakan penawaran. Saat ini, orang percaya bahwa mal adalah tempat terbaik untuk nongkrong dan entertainment. Bukan hanya tempat untuk berbelanja tetapi juga untuk sosial dan kegiatan rekreasi." (Monisha, Divyalakshmi, Divyaa, 2019, p. 56)

\section{Karakteristik Secara Fisik}

Setiap tempat adalah kombinasi unik dari karakteristik fisik, aktivitas, dan karakter yang menjadikannya unik. Karakteristik fisik meliputi aspek alam seperti topografi, cuaca, fauna dan elemen buatan manusia seperti konstruksi dan konfigurasi spasial aktivitas manusia termasuk dalam rutinitas atau peristiwa yang dilakukan orang di suatu tempat. Karakter atau genius loci terbentuk dari unsur-unsur yang membentuk suasana, atmosfer dan persepsi tempat dalam suatu budaya. Karakter adalah sesuatu yang memberikan sebuah lokasi sacredness dan humanity. (Seamon, 2011) 


\section{METODE}

\section{Sumber Data}

Data Primer

a. Pendataan secara manual dan sintesis dari hasil analisis untuk mencari kelurahan dengan mal terbanyak per-hektarnya;

b. Non-participant observation yang dilakukan terjun ke lapangan dalam kurun waktu tiga minggu untuk melakukan pencatatan pola aktivitas dan prefrensi partisipan di dalam malmal kawasan terpilih;

c. Kuisioner yang disebarkan secara daring melalui google forms, yang memuat pertanyaan seputar kawasan terpilih, bertujuan untuk memperoleh kejelasan pemisaan antara first, second dan third place bagi penduduk kawasan terpilih. Kuisioner juga akan disebarkan ke penduduk yang tempat tinggalnya berbatasan langsung dengan kawasan terpilih;

d. Wawancara yang pelaksanaannya lebih bebas serta terbuka untuk mengetahui makna third place bagi warga di kawasan terpilih, dan bagaimana prefrensi mereka terhadap third place kedepannya.

Data Sekunder

Data sekunder mencakup data statistik bersumber dari BPS (Badan Pusat Statistik), Property Research Reports oleh Colliers International Indonesia, PT. Summarecon Agung, jakartasmartcity.com, atrpbn.go.id dan katadata.com beserta studi pustaka dari sumbersumber terkait.

\section{Metode Perancangan}

a. Comparative study

Dilakukan untuk mendapatkan data tentang proyek sejenis untuk mengetahui beberapa prinsip dalam bangunan yang akan membantu proses perancangan ditambah dengan kajian teori topik terkait (Zainurrahman, 2013, p.107);

b. Evidence-based design

Menggunakan riset dan analisis dari lapangan sebagai metode untuk mendesain dengan maksud mencapai hasil terbaik;

c. Developing the concept of third placeness

Membaca ulang definisi third place gagasan Oldenburg dan mencari perkembangan yang ada saat ini dalam bidang teknologi, komunikasi dan cara bersosialisasi;

d. Integrating innovation with technology

Mempelajari karya yang sudah ada, mengevaluasi karya tersebut sehingga mampu memberikan inovasi dari hasil evaluasi dan melibatkan teknologi terbaru sebagai salah satu pendekatan untuk menuju desain akhir yang mumpuni.

\section{DISKUSI DAN HASIL}

Fasilitas Hiburan Kuisioner yang disebarkan juga memuat pertanyaan bagaimana warga Kelapa Gading menghabiskan waktu luangnya, dan dimana mereka cenderung menghabiskan waktu luangnya. Dua gambar dibawah ini adalah jawaban dari masingmasing pertanyaan:

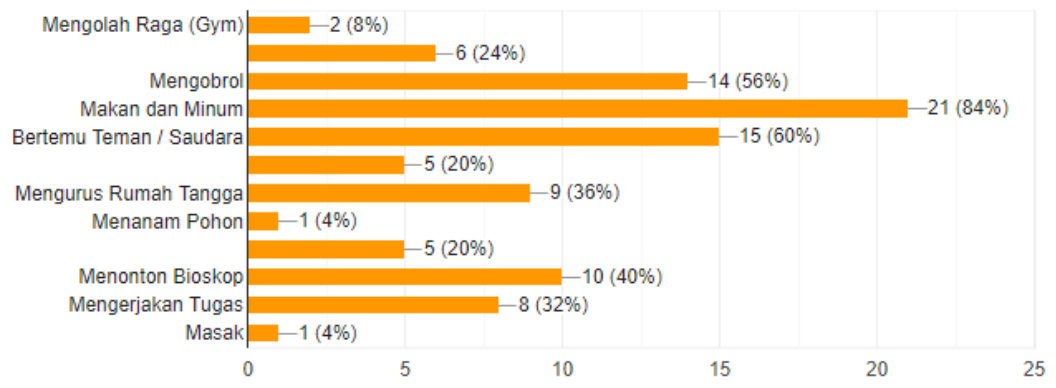

Gambar 1. Jawaban responden akan cara menghabiskan waktu luang. 


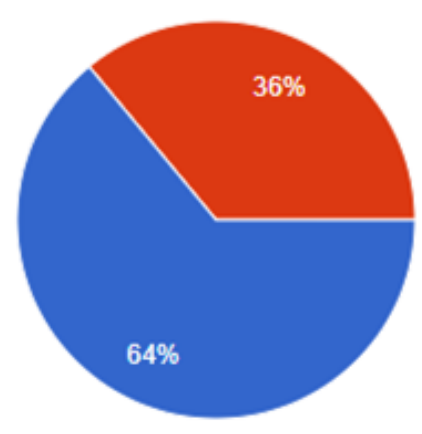

Gambar 2. Sebanyak 64\% responden cenderun menghabiskan waktunya di mal.

Sebagai penutup, berikut juga dipaparkan hasil non-participant observation yang dilakukan dalam kurun waktu tiga minggu untuk membuat behavioural map akan pengunjung mal-mal di kawasan Kelapa Gading. Hasil pengamatan yang digabung dengan wawancara pada responden yang diamati kemudian menghasilkan progam ruang sebagai berikut:

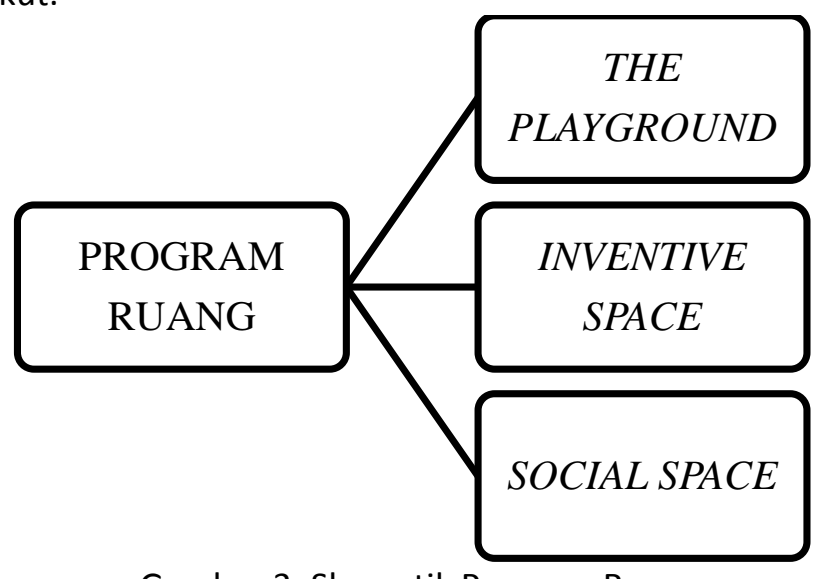

Gambar 3. Skematik Program Ruang

Keterangan:

a. THE PLAYGROUND

THE PLAYGROUND ditunjukkan terutama untuk remaja dan orang dewasa agar selalu bisaa kembali merasakan indahnya bermain dan mudahnya membentuk sebuah interaksi dari sebuah permainan. Program ruang didalam The Playground dibuat berdasarkan konsep bermain anak-anak yang akan mengajak pengunjung untuk bermain dari sisi kognitif, kreatif dan imajinatif, social dan fisik serta mempertemukan pengunjung dari segala usia;

b. INVENTIVE SPACE

INVENTIVE SPACE mengajak pengunjung untuk turut serta memperhatikan lingkungan dengan cara mempelajari secara mandiri konsep upcycle pada galeri bongkar pasang agar mampu mempelajari setiap komponen dari suatu benda dan mampu menginovasikan bahkan membuat hal baru didalam studio;

c. SOCIAL SPACE

SOCIAL SPACE merupakan ruang terbuka yang memiliki open theatre untuk menonton film secara bersama-sama. Film yang ditonton merupakan film pilihan yang terjadwal, serta diperbolehkan juga memutar film kreasi sendiri yang dapat dibuat pada area playground dengan memanfaatkan teknik stopmotion dan memanfaatkan lego sebagai pelatar dan penokohannya. 


\section{KESIMPULAN DAN SARAN}

Setelah melalui berbagai tahap dalam merancang proyek, dapat ditarik beberapa poin penting sebagai kesimpulan akhir:

a. Berbagai sumber data dengan berbagai metode yang konvensional maupun ekstrim perolehan bisa menenggelamkan, namun jika melihat dengan seksama maka akan terlihat berbagai keseempatan untuk melihat lebih dalam dan dari sudut pandang lain sehingga diperoleh hasil akhir yang unik;

b. Third place di kawasan perkotaan kerap mengalami pergeseran makna, yang selalu mengacu kepada shopping centre. Pergeseran ini tidak dapat dinilai baik positif maupun negatifnya karena kebahagiaan orang tergantung pada orang itu sendiri. Arsitek hanya mampu menawarkan sesuatu yang baru namun tidak bisa memaksakannya;

c. Sebagai seorang calon arsitek, kita tidak hanya memiliki kesempatan merancang sebuah bangunan dengan program yang sudah ada, namun kita punya kesempatan untuk membentuk masa depan seperti visi dan misi kita terhadap suatu wilayah. Pentingnya memikirkan program ruang secara matang dan tidak hanya mengikuti yang sudah ada akan membuahkan suatu aktivitas baru yang out of the box.

\section{REFERENSI}

Habermas, J. (1989). Structural Transformation of the Public Sphere: An Inquiry into a Category of Bourgeois Society. US: MIT Press.

Kaufman, C., Perlman, R., \& Speciner, M. (1995). Network security: Private communication in a public world. Englewood Cliffs, NJ: Prentice Hall.

Memarovic, N.et all (2014). Rethinking Third Places: Contemporary Design With Technology. The Journal of Community Informatics, 3-10.

Monisha, A.N., Divyalakshmi S., Dhivyaa M. (2019). Corresponding Author: Dr. Krithika J. The Conceptual Understanding of "Why Malls Are Not Preferred Anymore". IOSR Journal of Business and Management (IOSR-JBM) e-ISSN: 2278-487X, p-ISSN: 2319-7668. Volume 21, Issue 4. Ser. I, 54-58.

Myers, Peters (2012). Going Home: Essays, Articles, and Stories in Honour of the Andersons. Oak Hill College. ISBN 978-1-291-12167-4. London.

Oldenburg, Ray (1999). The Great Good Place. U.S.: Da Capo Press.

Seamon, D. (2011). Place Attachment and Phenomenology: The Synergistic Dynamism of Place. U.S: Kansas State University.

Weiser, M. (1991). The Computer for the 21st Century. Scientific American, 94-104.

Zainurrahman. (2013). Menulis: Dari Teori Hingga Praktik (Penawar Racun Plagiarisme). Bandung: Alfabeta. 